\title{
Comparison of The Risk Factors For Falls Among Older Adults Between Urban and Rural Areas of Shantou City, China
}

\section{Xiaodong Chen}

Shantou University Medical College

Zeting Lin

Shantou University Medical College

\section{Ran Gao}

Shantou University Medical College

\section{Yijian Yang}

The Chinese University of Hong Kong

Liping Li ( $\square$ Ipli@stu.edu.cn )

Shantou University Medical College

\section{Research article}

Keywords: older adults, urban and rural, falls, risk factors

Posted Date: September 21st, 2020

DOI: https://doi.org/10.21203/rs.3.rs-72830/v1

License: (c) (i) This work is licensed under a Creative Commons Attribution 4.0 International License. Read Full License 


\section{Abstract}

Background: To investigate the prevalence of falls and risk factors among older adults in urban and rural areas and to facilitate the design of fall prevention interventions.

Methods: We used cluster random sampling to investigate the sociodemographic information, living habits, medical history, and falls among 649 older adult participants. Univariable and multivariable logistic regression was used to examine fall risk factors in urban and rural areas.

Results: The fall rate and rate of injury from falls among older adults in urban areas were $27.3 \%$ and $18.6 \%$, respectively, which were higher than those in rural areas $(17.0 \%$ and $12.2 \% ; P<0.05)$. Multivariable analysis showed that the risk factors for falls among urban older adults included a high school or below education level (OR=3.737, 95\% Cl: 1.503 9.291); diabetes medicine use ( $O R=4.518,95 \% \mathrm{Cl}$ : 1.228 16.626); incontinence ( $O R=8.792,95 \% \mathrm{Cl}$ : 1.894 40.824); lack of fall prevention education $(O R=$ 11.907, 95\% Cl: $1.321 \otimes 107.354) ;$ and reduced balance function $(O R=3.901,95 \% \mathrm{Cl}$. 1.894 7.815). The risk factors among rural older adults included a previous nonfarming occupation $(O R=2.496,95 \% \mathrm{Cl}$. 1.416 4.398); incontinence ( $O R=11.396,95 \% \mathrm{Cl}$. 1.901 68.327); poor living environment ( $O R=3.457,95 \%$ Cl: 1.488 8.033); and reduced balance function $(O R=4.260,95 \% \mathrm{Cl}$. $2.361 \sim 7.688)$.

Discussion: The rate of falls among older adults in urban areas is higher than that in rural areas of Shantou City. Fall prevention in urban areas should target older adults with low education and modify the diabetes medication use. Interventions should focus on improving the home environment of older adults in rural areas.

\section{Background}

According to a report from the World Health Organization (WHO), 646,000 people die from falls every year worldwide, the majority of whom are adults over 65 years old; falls have become the second largest cause

of unintentional injury death after to road traffic injuries ${ }^{[1]}$. The WHO notes that falls are the main threat to the health of older adults throughout the world and the leading cause of injuries and injury-related mortality. The consequences of falls among older adults are not only physical trauma and disability but also a series of psychological problems, such as fear of falls, depression and anxiety ${ }^{[2]}$. The high incidence of falls, disability and mortality in older adults suggests the urgent need for preventative measures.

According to China's National Bureau of Statistics, by the end of 2018, approximately 249 million of Chinese citizens were older adults aged 60 and over, accounting for $17.9 \%$ of the population; among these, approximately 167 million individuals were aged 65 and over, accounting for $11.9 \%$ of the total population ${ }^{[3]}$. Aging is a global issue, and China also faces this serious problem. The health care costs for older adults continue to increase, bringing a burden to the family and society. The Centers for Disease Control and Prevention (CDC) in the United States reports that more than one quarter of older adults over 65 years old fall every year, and every 20 minutes, an older adult dies from a fall. More than 3 million people 
(approximately $1 \%$ ) receive fall injury treatment in the emergency room every year, and the total medical cost of falls exceeds 50 billion US dollars ${ }^{[4]}$.

Falls among older adults are the result of the interaction of various factors. According to previous studies, these consist of both internal and external risk factors. Internal risk factors include physiological factors (balance, vision, etc.), pathological factors (stroke, Parkinson's disease, etc.), pharmaceutical factors (antidepressant use, hypoglycemic agent use, etc.), and psychological factors (depression, anxiety, etc.). External factors include environmental factors (dim lighting, lack of handrails in bathrooms, etc.) and social factors (income level, living alone, etc.) ${ }^{[5]}$. There are many studies on falls among older adults in foreign countries, and some developed countries have carried out numerous interventions to reduce the occurrence of falls among older adults and the injuries they cause ${ }^{[6,7,8]}$. However, due to the ethnic and regional differences between China and other countries, the factors that affect falls among older adults may also differ.

According to the sixth census in China (2010), the size of the rural population is 660 million, among whom nearly 100 million individuals are over 60 years old, accounting for $15.15 \%$ of the population ${ }^{[9]}$. However, domestic research has mainly focused on the investigation of older adults in developed cities, including Beijing, Shanghai, and Shenzhen ${ }^{[10,11,12]}$. There is a lack of investigation of older adults in rural areas. Older adults in rural areas are an underserved group; many policies and services for older adults are prioritized for those living in urban areas, and medical conditions, income levels and living environments in rural areas are considered worse than their urban counterparts. Therefore, older adults in rural areas are typically ignored when compared to those living in cities. At the same time, the cultural levels and living habits and environments of older adults in urban and rural areas are also different ${ }^{[13,14]}$. Therefore, the aim of this study was to investigate the fall status among older adults Shantou City and to compare the different risk factors between urban and rural areas to guide fall prevention and health decision-making for these two populations of older adults.

\section{Methods}

\section{Subjects}

Older adults were recruited from the urban and rural areas of Shantou City, China. Inclusion criteria were (1) age $\geq 60$ years; (2) ability to walk independently or rely on auxiliary facilities; (3) residence in the local area for 1 year; (4) ability to understand the survey and cooperate with the completion of the assessment; and (5) willingness to participate in the survey and research and ability to sign informed consent. Exclusion criteria included older adults who (1) were unable to walk in the past year; (2) had severe illness or dysfunction; (3) were unable to complete medical examinations and assessment projects; and (4) had cognitive dysfunction and thus an inability to answer questions correctly.

\section{Definition of fall}


A fall is a sudden involuntary or unintentional change of body position, resulting in a drop to the ground or a lower plane ${ }^{[5]}$. According to the classification of falls from the International Classification of Diseases (ICD-10), falls include the following two categories: (1) a fall from one plane to another and (2) a fall onto the same plane ${ }^{[5]}$.

\section{Study design}

We conducted a cross-sectional study from April 2018 to December 2018. A cluster random sampling method was used to recruit older adults aged 60 and over in Jinping District and Chenghai District of Shantou City with whom we conducted a face-to-face survey. The researchers filled out the questionnaires because older adults with low education levels and poor visual acuity could not fully understand the content of the questionnaire by themselves. Interviews were conducted in the participants' homes by trained researchers using local dialects in plain language.

\section{Survey contents}

Demographic information included gender, age, occupation, and education level of the participants. Health status included hearing, vision, medication, and incontinence. Information on fall situations included the incidence of falls and injuries related to falls in one year, which was obtained with a self-report form. If the participant had fallen within the past year, a fall situation form was required to be completed. The fall situation form included fall times, places, locations, and severity. Information about living environment was based on a survey from the "Evaluation Form for Preventing Older Adults from Falling in the Home Environment Risk Factors" ${ }^{[5]}$ via direct observation by the researcher, including (1) the floors and passageways (whether sundries are piled up in the corridor and antiskid floor tiles are used); (2) the living room (sufficient lighting, armrests for commonly used chairs, etc.); (3) the bedroom (dual control lighting switches, telephone installed at the head of the bed, etc.); (4) the kitchen (good ventilation and installed telephone) and (5) the bathroom (smooth drainage, armrests beside the toilet, etc.). The number of home environment issues was divided into three levels: (1) $\leq 1$; (2) 2-3; and (3)>3. We also used the Older Adults Balance Ability Test Scale to assess the balance ability of older adults and the risk of falling ${ }^{[5]}$. Measurements were selected from the "Older Adults Balance Ability Test Scale" in the "Technical Guide for Falling Interventions for Older Adults", which include the following three parts: (1) static balance ability; (2) posture control ability; and (3) dynamic balance ability. The classification of the scale was as follows: (1) 0 points: good balance ability; (2) 1-4 points: acceptable balance ability but increased risk of falling; (3) 516 points: greatly weakened balance ability and greater risk of falling; and (4) 17-24 points: poor balance ability and greatest risk of falling and injury ${ }^{[5]}$.

\section{Data analysis}

EpiData 3.1 was used for double data entry verification. SPSS 24.0 was used for data analysis. Classification (categorical) data are described by frequency and percentage. Measurement (continuous) data are described by the mean and standard deviation $(X \pm S D)$. Comparisons of percentages were performed by the $X^{2}$ test. The risk factors for falls were examined using unconditional logistics regression 
analysis (maximum likelihood forward method), and the odds ratio $(O R)$ and its $95 \%$ confidence interval $(\mathrm{Cl})$ were calculated. The explanatory variables were first analyzed by univariable analysis. Factors with statistical significance $(P<0.05)$ were entered into a model for multivariable analysis. The standard variable $a$ was introduced as 0.05 , and the standard variable excluded as $\beta$ was 0.1 .

\section{Results}

A total of 649 older adults were surveyed from urban and rural areas in this study. A total of 254 questionnaires were issued in urban areas and 231 were returned, resulting in a response rate of $90.9 \%$; 451 questionnaires were issued in rural areas and 418 were returned, resulting in a response rate of $92.7 \%$. The survey respondents in the urban areas were 60-83 years old, with an average age of 67.39 (SD 4.61) years, and the survey respondents in the rural areas were 60-88 years old, with an average age of 72.71 (SD 7.62) years. The demographic characteristics of the urban and rural older adult participants are shown in Table 1. 
Table 1

Demographic characteristics of older adults in Shantou City

\begin{tabular}{|c|c|c|c|c|c|}
\hline \multirow[t]{2}{*}{ Characteristics } & \multicolumn{2}{|c|}{ urban areas } & \multicolumn{2}{|c|}{ rural areas } & \multirow[t]{2}{*}{ p-value } \\
\hline & $\mathrm{n} \%$ & & $\mathrm{n} \%$ & & \\
\hline Gender & & & & & 0.457 \\
\hline Male & 67 & 29.0 & 133 & 31.8 & \\
\hline Female & 164 & 71.0 & 285 & 68.2 & \\
\hline Age & & & & & 0.063 \\
\hline $60-69$ & 170 & 73.6 & 282 & 67.5 & \\
\hline $70-79$ & 54 & 23.4 & 106 & 25.4 & \\
\hline$\geq 80$ & 7 & 3.0 & 30 & 7.2 & \\
\hline Education level & & & & & $<0.01$ \\
\hline High school and below & 172 & 74.5 & 355 & 85.0 & \\
\hline College and above & 59 & 25.5 & 63 & 15.0 & \\
\hline Previous occupation & & & & & $<0.01$ \\
\hline farmer & 8 & 3.5 & 230 & 55.0 & \\
\hline worker & 113 & 48.9 & 120 & 28.7 & \\
\hline teacher & 22 & 9.5 & 14 & 3.3 & \\
\hline cadres or civil servants & 62 & 26.8 & 9 & 2.2 & \\
\hline other & 26 & 11.2 & 45 & 10.8 & \\
\hline Average monthly income & & & & & $<0.01$ \\
\hline Less than 2500 yuan & 74 & 32.1 & 397 & 95.5 & \\
\hline $2500-3500$ yuan & 93 & 40.2 & 20 & 4.8 & \\
\hline $3500-5000$ yuan & 37 & 16.0 & 1 & 0.2 & \\
\hline 5000 yuan or more & 27 & 11.7 & 0 & 0.0 & \\
\hline Living alone & & & & & $<0.01$ \\
\hline Yes & 27 & 11.7 & 118 & 28.2 & \\
\hline No & 204 & 88.3 & 300 & 71.8 & \\
\hline
\end{tabular}

Comparisons between urban and rural older adults in Shantou City 
Among the 649 older adult participants, 134 had fallen at least once in the past year, an incidence of $20.65 \%$; 94 had received injuries as a result of falls, for an injury rate of $14.48 \%$. See Table 2 for the fall and injury rates in both urban and rural areas.

Table 2

Comparisons between urban and rural older adults in Shantou City

\begin{tabular}{|c|c|c|c|c|c|c|}
\hline Area & $\begin{array}{l}\text { Fall } \\
\text { (N) }\end{array}$ & Fall rate (\%) & $P$ & Injuries (N) & Injury rate (\%) & $P$ \\
\hline Urban areas & 63 & 27.3 & \multirow[t]{2}{*}{0.02} & 43 & 18.6 & \multirow[t]{2}{*}{0.026} \\
\hline Rural areas & 71 & 17.0 & & 51 & 12.2 & \\
\hline
\end{tabular}

Analysis of risk factors for falls among older adults in the past year

Univariable analysis of risk factors for falls among older adults in urban and rural areas in Shantou City in the past year.

Univariable analysis showed that six factors were associated with older adult falls in urban areas in the past year, including education level, whether they were afraid of falling, whether they took diabetes drugs, whether they had incontinence, whether they had received fall prevention education, and balance function $(P<0.05)$. Six factors were also associated with older adult falls in rural areas in the past year, including their previous occupation (farmer or nonfarmer), whether they were afraid of falling, whether they had incontinence, whether they used canes, living environment problems and balance ability $(P<0.05)$ (see Supplementary Table 1).

\section{Multifactor analysis of risk factors for falls among older adults in the past year.}

Significant variables $(P<0.05)$ from the univariable analysis as well as age and gender were included in the multivariable logistic regression analysis, and a stepwise method (partial maximum likelihood forward method) was used to determine variables for inclusion. The variable standard $=0.05$ and the variable exclusion standard $=0.1$ were used. The dependent variable was whether or not a fall occurred.

Multivariable logistic regression analysis showed that low education level, diabetes medication use, incontinence, lack of fall prevention education, and poor balance ability were associated with risk of fall among the urban older adults (Table 3). Nonfarming as the previous occupation, incontinence, home environment issues, and poor balance ability were related to the risk of fall among the rural older adults (Table 4). 
Table 3

Multifactor logistic regression analysis for older adults falling in urban areas in the past year

\begin{tabular}{|c|c|c|c|c|c|c|c|c|}
\hline Factor & $\begin{array}{l}\text { Comparison } \\
\text { group }\end{array}$ & $\begin{array}{l}\text { Reference } \\
\text { group }\end{array}$ & $\beta$ & SE & Wald & $\begin{array}{l}\text { p- } \\
\text { value* }\end{array}$ & OR & $95 \% \mathrm{Cl}$ \\
\hline $\begin{array}{l}\text { Education } \\
\text { level }\end{array}$ & $\begin{array}{l}\text { High school } \\
\text { and below }\end{array}$ & $\begin{array}{l}\text { College } \\
\text { and } \\
\text { above }\end{array}$ & 1.318 & 0.465 & 8.046 & $0.005^{\star}$ & 3.737 & $\begin{array}{l}1.503- \\
9.291\end{array}$ \\
\hline $\begin{array}{l}\text { Diabetes } \\
\text { medicine } \\
\text { use }\end{array}$ & Yes & No & 1.508 & 0.665 & 5.147 & $0.023^{*}$ & 4.518 & $\begin{array}{l}1.228- \\
16.626\end{array}$ \\
\hline Incontinence & Yes & No & 2.174 & 0.783 & 7.700 & $0.006^{*}$ & 8.792 & $\begin{array}{l}1.894- \\
40.824\end{array}$ \\
\hline $\begin{array}{l}\text { Fall } \\
\text { prevention } \\
\text { education }\end{array}$ & No & Yes & 2.477 & 1.122 & 4.874 & $0.027 *$ & 11.907 & $\begin{array}{l}1.321- \\
107.354\end{array}$ \\
\hline Balance & Reduced & Normal & 1.361 & 0.354 & 14.745 & $<.001 *$ & 3.901 & $\begin{array}{l}1.947- \\
7.815\end{array}$ \\
\hline Constant & & & -5.438 & 1.236 & 19.358 & $\begin{array}{l}<.001 \\
0.01\end{array}$ & 0.004 & \\
\hline \multicolumn{9}{|c|}{ Notes: OR: odds ratio, 95\% Cl: 95\% confidence interval. } \\
\hline$\star \mathrm{P}<.05$ & & & & & & & & \\
\hline
\end{tabular}


Table 4

Multifactor logistic regression analysis for older adults falling in rural areas in the past year

\begin{tabular}{|c|c|c|c|c|c|c|c|c|}
\hline Factor & $\begin{array}{l}\text { Comparison } \\
\text { group }\end{array}$ & $\begin{array}{l}\text { Reference } \\
\text { group }\end{array}$ & $\beta$ & SE & Wald & $\begin{array}{l}\text { p- } \\
\text { value* }\end{array}$ & OR & $95 \% \mathrm{Cl}$ \\
\hline $\begin{array}{l}\text { Previous } \\
\text { occupation }\end{array}$ & nonfarmer & farmer & 0.915 & 0.289 & 10.010 & $0.002^{*}$ & 2.496 & $\begin{array}{l}1.416- \\
4.398\end{array}$ \\
\hline Incontinence & Yes & No & 2.433 & 0.914 & 7.090 & $0.008^{*}$ & 11.396 & $\begin{array}{l}1.901- \\
68.327\end{array}$ \\
\hline \multirow{3}{*}{$\begin{array}{l}\text { Home } \\
\text { environment } \\
\text { issues }\end{array}$} & & $\leq 1$ & & & 8.432 & $0.015^{\star}$ & & \\
\hline & $2-3$ & & 0.284 & 0.311 & 0.832 & 0.362 & 1.329 & $\begin{array}{l}0.722- \\
2.446\end{array}$ \\
\hline & $>3$ & & 1.240 & 0.430 & 8.317 & $0.004^{*}$ & 3.457 & $\begin{array}{l}1.488- \\
8.033\end{array}$ \\
\hline Balance & Reduced & Normal & 1.449 & 0.301 & 23.162 & $\varangle 0.001^{*}$ & 4.260 & $\begin{array}{l}2.361- \\
7.688\end{array}$ \\
\hline Constant & & & -3.254 & 0.375 & 75.449 & $\bowtie 0.001$ & 0.039 & \\
\hline \multicolumn{9}{|c|}{ Notes: OR: odds ratio, 95\% Cl: 95\% confidence interval. } \\
\hline$<.05$ & & & & & & & & \\
\hline
\end{tabular}

\section{Discussion}

The incidence of falls among older adult people in Shantou City in the past year was $20.65 \%$, which was higher than the result of a meta-analysis in China (18.3\%) ${ }^{[15]}$, lower than that of Cape Town $(26.4 \%)$ in South Africa ${ }^{[16]}$ and close to that of South Korea $(20.95 \%)^{[17]}$ and Japan $(20.8 \%)^{[18]}$. The fall rate and rate of injury from falls among older adults in urban areas were higher than those among older adults in rural areas. This is consistent with the study by $\mathrm{Li}^{[12]}$ but different from the study by $\mathrm{He}^{[14]}$. The discrepancies may be due to the comprehensive influence of regional culture, gender structure, age structure, education level and economic income of older adults, which suggests the need to carry out intervention measures according to specific fall circumstances in different regions.

\section{Similar risk factors for both areas}

Incontinence was a risk factor for falls in both urban $(O R=8.792)$ and rural areas $(O R=11.396)$. This is consistent with the results from Choi and Kim's studies ${ }^{[17,19]}$, indicating that incontinence is a common risk factor across different regions and populations. Incontinence causes a corresponding increase in the frequency of urination in older adults, which itself is increased further due to an increased water intake resulting from the hot climate in Shantou and the rich tea culture in China. This increased frequency of 
urination, especially at night, greatly increases the risk of falling. Therefore, targeted intervention for older adults with incontinence or urinary system infection may effectively prevent and reduce the risk of falls.

Decreased balance ability was a risk factor for falls in both urban $(O R=3.901)$ and rural areas $(O R=$ 4.260). Our finding is consistent with the results of Zhao and Hou's studies ${ }^{[20,21]}$, in which they found that the balance ability of older adults decreases with age. This is due to the structural and functional impairment and degradation of the bones, joints, ligaments and muscles with age ${ }^{[5]}$. At the same time, degradation of the central nervous system degeneration and osteoporosis affect older adults' muscle strength, sensation, coordination, reaction times, and ability to move ${ }^{[5]}$. All of these factors contribute to the increased risk of falling. Physical exercise has been shown to improve balance in older adults, including Taijiquan ${ }^{[22]}$. Regular physical exercise helps enhance muscle strength and balance ${ }^{[23]}$. In addition, group-based exercise helps older adults interact and communicate, which improves their mental health and confidence and reduces their fear of falling ${ }^{[24]}$.

\section{Different risk factors between rural and urban areas}

Older adults with lower education levels and who lack fall prevention education have a higher risk of fall. The ORs for these two factors were 3.737 and 11.907 for the urban area, respectively. This is consistent with the findings of Huang ${ }^{[25]}$. The proportion of older adults who have received fall prevention education in Shantou City is only $16.80 \%$. Older adults with higher education levels generally have a higher standard of living and a greater sense of self-protection ${ }^{[26]}$. Older adults with low education levels are less aware of the knowledge of fall prevention. Their low level of consciousness may increase their exposure to falls. For older adults in rural areas, due to their overall low level of education and limited access to fall prevention education, the level of education and whether they had received fall prevention education were not significantly associated with the incidence of falling. Our results suggest that more education should be provided to older adults to prevent falls, especially in less educated and underdeveloped areas. More attention should be paid to the popularization and dissemination of fall prevention programs, and targeted health education should be carried out to improve the awareness among older adults to prevent falls.

Taking diabetes medication increased the risk of falling by 4.518 times compared to not taking diabetes medicine, which is consistent with the results of Berlie's study ${ }^{[27]}$. Diabetes occurs in older adults after taking too much diabetes medication. Studies have found that patients with diabetes have twice the risk of diabetes than those without diabetes ${ }^{[28]}$. Older adults with diabetes often have complications and take multiple drugs for many years. One study showed that the side effects of one or more drugs can increase the risk of falls in older adults ${ }^{[29]}$. Older adults have weakened memory, take more chronic medications daily, and lack correct guidance from a doctor. In the process of taking the medication, they are prone to inappropriate doses and an increased risk of falling. Therefore, we should pay attention to the daily medication of older adults and provide guidance and education on medication management, especially those with diabetes. 
Previous occupation as a farmer was a protective factor for falls among rural older adults. One explanation is that past engagement in labor was a protective form of physical exercise, which may have improved their physical fitness over time ${ }^{[12]}$. However, when we compared and analyzed previous occupation and balance, we did not find an association between older adults who used to be farmers and their balance ability. The possible reason is that the cause of fall is affected by many factors and does not only depend on the level of balance. On the other hand, few older adults in urban areas were previously employed as farmers, which may explain the lack of statistical significance of their occupation on fall risk.

This study found that rural older adults who had more than 3 home environment issues had a 3.457-fold higher risk of falling than those with 1 or no home environment issues. Sophonratanapokin's study ${ }^{[30]}$ also indicated that a high number of home environment issues was a risk factor for falls among older adults. Our investigation found that the living environment of rural older adults in Shantou City is much worse than that of urban older adults. The living environment of rural older adults (floor and passageways, living room, bedroom, kitchen, and bathroom) is littered with many potential safety hazards. Some households even lack separate toilets, which greatly increases the risk of older adults falling. This study found that $28.2 \%$ of rural older adults lived alone, and nearly half of falls occurred at home. Therefore, there is an urgent need to conduct a comprehensive assessment of the home environment of older adults and identify hazards to reduce their risk of falls.

The limitations of this study mainly include the following: First, the questionnaire survey covered falls in the past year, which could be affected by the worsening memory of older adults and therefore recall bias. However, this is a common issue for most survey studies. Considering that older adults of Shantou City are not well educated, especially rural older adults who are mostly illiterate, the questionnaires were filled out by the researchers asking the questions to the older adults. Our investigators have been trained for consistency in data collection to reduce subjectivity. To address the memory problems of older adults, the researchers made multiple inquiries in local dialects to reduce recall bias. Second, falls among older adults are the result of the interaction of multiple factors. However, this study focused on investigating the internal risk factors for older adults but less on external risk factors.

\section{Conclusions}

Older adults in urban areas have a higher rate of falling than those in rural areas of Shantou City. Our focus for fall prevention interventions should target older adults with low education levels and include instructions for taking diabetes medicine. Interventions in rural areas should focus on improving the living environment of older adults. There are similarities and differences in the risk factors among older adults in different regions. Targeted interventions for different older adult populations may be more effective in reducing the risk of falls.

\section{Abbreviations}

OR: Odds ratio

WHO: World Health Organization 
CDC: Centers for Disease Control and Prevention

ICD-10: International Classification of Diseases

95\%Cl: 95\% Confidence interval

\section{Declarations}

\section{Ethics approval and consent to participate}

Ethics Committee: Shantou University Medical College(SUMC-2018-41)

\section{Consent for publication}

Not applicable

\section{Availability of data and materials}

The datasets used and/or analysed during the current study are available from the corresponding author on reasonable request.

\section{Competing interests}

The authors declare that they have no competing interests.

\section{Funding}

None.

\section{Authors' contributions}

L.L.P., C.X.D., L.Z.T. and G.R. designed the study; C.X.D., L.Z.T. and G.R. collected the data; C.X.D. and L.Z.T. made data analyses and interpretation, L.L.P. supervised the study; C.X.D. wrote the manuscript draft; L.L.P. and Y.Y.J. made the critical revision of the manuscript.All authors have read and approved the manuscript.

\section{Acknowledgements}

The authors wish to thank the Longdu Health Center and Shantou Elderly University.

\section{References}

1. World Health Organization. Falls. 2018. https://www.who.int/news-room/fact-sheets/detail/falls.

2. White UE, Black AA, Wood JM, et al. Fear of falling invision impairment. Optom Vis Sci; 2015;92(6):730-5. DOI:10.1097/OPX.0000000000000596.

3. National Bureau of Statistics of China. (2019). Annual data. http://data.stats.gov.cn/index. 
4. US Centers for Disease Control and Prevention.(2016). About CDC's STEADI (Stopping Elderly Accidents, Deaths, \& Injuries) Initiative. https://www.cdc.gov/steadi/about.html. Published September 20.

5. China Disease Prevention and Control Center.(2011). Technical guidelines. for falls intervention in the elderly. http://www.nhc.gov.cn/wjw/gfxwj/201304/729e74b51ab5434c965ec03164eca46d.shtml.

6. Hong J, Kong HJ, Yoon HJ. Web-Based Telepresence Exercise Program for Community-Dwelling Elderly Women With a High Risk of Falling: Randomized Controlled Trial. Jmir Mhealth Uhealth. 2018;6(5):e132. DOI:10.2196/mhealth.9563.

7. Mirelman A, Rochester L, Maidan I, et al. Addition of a non-immersive virtual reality component to treadmill training to reduce fall risk in older adults (V-TIME): a randomised controlled trial. The Lancet. 2016;388:1170-82. DOI:10.1016/S0140-6736(16)31325-3.

8. Tricco AC, Thomas SM, Veroniki AA, et al. Comparisons of Interventions for preventing falls in older adults: a systematic review and meta-analysis. JAMA. 2017;318:1687-99.

DOI:10.1001/jama.2017.15006.htm.

9. National Bureau of Statistics. Tabulation on the 2010 population census of the people's republic of China. Beijing: China Statistics Press; 2012.

10. Zhou BY, Shi J, Yu PL. Consequence and risk factors of falls-related injuries in community-dwelling elderly in Beijing [in Chinese]. Chinese Journal of Epidemiology. 2013;34(8):778-81.

DOI:10.1111/jgs.12438.10.16117/j.cnki.31-1974/r.201805027

11. Dai Y, Wang ZY, Zhang YY, et al. Investigation on Falls of Elderly and KAP in Yangpu District of Shanghai [in Chinese]. Health Education and Health Promotion, 2018, 13(05): 461 - 46.

DOI:10.16117/j.cnki.31-1974/r.201805027.

12. Zhou H, Peng K, Tiedemann A, et al. Risk factors for falls among older community dwellers in Shenzhen, China [in Chinese]. Inj Prev. 2019;25(1):31-5. DOl:10.1136/injuryprev-2017-042597.

13. Li FF, Zhou DD, Ye ZZ, et al. Epidemiologic characteristics of fall in the elderly in urban and rural areas in Shanghai [in Chinese]. Chinese Journal of Epidemiology. 2019;40(7):779-85.

DOI:10.3760/cma.j.issn.0254-6450.2019.07.009.

14. He J. (2015). Incidence and risk factor analysis of fall among the elderly in urban and rural Communities [dissertation]. Ningxia Medical University.

15. Gao ML, Song YT. Meta-analysis of the prevalence of fall in elderly in China [in Chinese]. Beijing Medical Journal. 2014;36(10):796-8. DOI:10.15932/j.0253-9713.2014.10.051.

16. Kalula SZ, Ferreira M, Swingler GH, et al. Risk factors for falls in older adults in a South African Urban Community. BMC Geriatrics. 2016;16(1):51. DOI:10.1186/s12877-016-0212-7. Risk Factors for Falls in Older Korean

17. Choi EJ, Kim SA, Kim NR, et al. Risk Factors for Falls in Older Korean. Adults. The 2011 Community Health Survey. J Korean Med Sci, 2014, 29(11). DOI:10.3346/jkms.2014.29.11.1482.

18. Masumoto T, Yamada Y, Yamada M, et al. Fall risk factors and sex differences among communitydwelling elderly individuals in Japan. A Kameoka study. Jpn J Public Health. 2015;62(8):390-401. 
DOI:10.11236/jph.62.8_390.

19. The association of lower urinary tract Kim KS, Nam JW, Choi BY, et al. The association of lower urinary tract. symptoms with incidental falls and fear of falling in. later life: The Community Health Survey. Neurourology Urodynamics. 2018;37(2):775-84. DOI:10.1002/nau.23345.

20. Zhao YC, (Lucy), Alderden J, Lind BK et al A Comprehensive Assessment of Risk Factors for Falls in Community-Dwelling Older Adults. Journal of Gerontological Nursing, 2018, 4(10): 40-48. DOI:10.3928/00989134-20180913-04. Evaluation of an inpatient fall risk

21. Hou WH, Kang $\mathrm{CM}, \mathrm{Ho} \mathrm{MH}$, et al. Evaluation of an inpatient fall risk. screening tool to. identify the most critical fall risk factors in inpatients. J Clin Nurs. 2017;26(5-6):698. DOI:10.1111/jocn.13510.

22. Li F, Harmer P, Fitzgerald K, et al. Effectiveness of a therapeutic Tai Ji Quan intervention vs a multimodal exercise intervention to prevent falls among older adults at high risk of falling: a randomized clinical trial. JAMA Intern Med. 2018;178:1301-10.

DOI:10.1001/jamainternmed.2018.3915.

23. Hwang HF, Chen SJ, Lee-Hsieh J, et al. Effects of Home-Based Tai Chi and Lower Extremity Training and Self-Practice on Falls and Functional Outcomes in Older Fallers from the Emergency DepartmentA Randomized Controlled Trial. J Am Geriatr Soc. 2016;64(3):518-25. DOI:10.1111/jgs.13952.

24. Kendrick $D$, Kumar $A$, Carpenter $\mathrm{H}$, et al. Exercise for reducing fear of falling in older people living in the community. Cochrane Database Syst Rev. 2014;28(11):CD009848.

DOI:10.1002/14651858.CD009848.pub2.

25. Huang LM, Jiang YG, Zhu MY, et al. Assessment of Fall-related Knowledge, Attitude, Behaviorr and Perception of Elderly People in Songjian District, Shanhai [in Chinese]. Health Education Health Promotion. 2019;14(05):398-401 + 408. DOI:10.16117/j.cnki.31-1974/r.201905006.

26. Lai ET, Yu R, Woo J. The Associations of Income, Education and Income Inequality and Subjective Well-Being among Elderly in Hong Kong-A Multilevel Analysis. Int J Environ Res Public Health. 2020;17(4):1271. DOI:10.3390/ijerph17041271.

27. Berlie HD, Garwood CL. Diabetes medications related to an increased risk of falls and fall-related morbidity in the elderly. Ann Pharmacother. 2010;44(4):712-7. DOI:10.1345/aph.1M551.

28. Sumesh K, Hugh K, Susan C, et al. Association Between Hypoglycemia and Fall-Related Events in Type 2 Diabetes Mellitus: Analysis of a U.S. Commercial Database. Journal of Managed Care Specialty Pharmacy. 2015;21(3):243-53. DOI:10.18553/jmcp.2015.21.3.243.

29. Association between Dhalwani NN, Fahami R, Sathanapally H, et al. Association between. polypharmacy. and falls in older adults: a longitudinal study from England. Bmj Open. 2017;7(10):e016358. DOI:10.1136/bmjopen-2017-016358.

30. Sophonratanapokin B, Sawangdee Y, Soonthorndhada K. Effect of the living environment on falls among the elderly in Thailand. Southeast Asian Journal of Tropical Medicine Public Health. 2012;43(6):1537-47. DOI:10.1016/j.bjid.2012.07.015.

\section{Supplementary Files}


This is a list of supplementary files associated with this preprint. Click to download.

- supplementalfile.docx 